\title{
Characterization of mutations in aclacinomycin A-non-producing Streptomyces galilaeus strains with altered glycosylation patterns
}

\author{
Kaj Räty, ${ }^{1}$ Anne Hautala, ${ }^{2}$ Sirke Torkkell, ${ }^{1}$ Jaana Kantola, ${ }^{2}$ \\ Pekka Mäntsälä, ${ }^{1}$ Juha Hakala $^{2} \dagger$ and Kristiina Ylihonko ${ }^{2}$
}

Author for correspondence: Kaj Räty. Tel: +3582333 6856. Fax: +35823336860.

e-mail:kaj.raty@utu.fi

1 Department of Biochemistry and Food Chemistry, University of Turku, Vatselankatu 2, FIN-20014, Turku, Finland

2 Galilaeus Oy, PO Box 113, FIN-20781, Kaarina, Finland
In this study a set of Streptomyces galilaeus ATCC 31615 mutants was characterized, which are incapable of synthesizing some or all of the deoxyhexose sugars of aclacinomycin A. Complementation experiments with the the mutant strains H026, H038, H039, H054, H063, HO65 and HO75 were carried out with glycosylation genes previously derived from the wild-type S. galilaeus. Mutations in strains $\mathrm{H038}, \mathrm{HO63}$ and $\mathrm{HO} 5$ were complemented with single PCR-amplified genes. Furthermore, amplification and sequencing of the corresponding genes from the mutant strains revealed single point mutations in the sequences. First, in $\mathrm{H038}$ a transition mutation in aknQ, encoding a putative dTDP-hexose 3-ketoreductase, causes an amino acid substitution from glycine to aspartate, suppressing the biosynthesis of both 2-deoxyfucose and rhodinose and thus leading to the accumulation of aclacinomycin T with rhodosamine as its only sugar. Second, in H063, which accumulates aklavinone without a sugar moiety, amino acid substitution occurs, with threonine being substituted by isoleucine in dTDP-glucose synthase, the first enzyme participating in deoxyhexose biosynthesis, encoded by aknY. Third, a nonsense mutation in aknP leads to truncated dTDP-hexose 3-dehydratase in H075, which is incapable of synthesizing rhodinose. In addition, mutants $\mathrm{HO54}$ and H065, which accumulate aclacinomycins without aminosugars, were complemented by a gene for an aminotransferase, aknZ. Characterization of the nature of the mutations adds to the usefulness and value of the mutants in the analysis of gene function and in the creation of novel compounds by combinatorial biosynthesis. Furthermore, these results strengthen the assignments of akn gene products and enlighten the biosynthetic pathway for deoxyhexoses.

Keywords: anthracycline, complementation, deoxyhexose pathway

\section{INTRODUCTION}

Aclacinomycins are a group of anthracycline antibiotics. Along with several other anthracyclines, aclacinomycins exhibit powerful cytotoxic and antibacterial properties. A representative member, aclacinomycin A (aclarubicin)

\footnotetext{
†Present address: Lividans Oy, Lemminkäisenkatu 30, FIN-20520 Turku, Finland.

Abbreviations: Akv, aklavinone; dF, 2-deoxyfucose; NTG, $N$-methyl- $N^{\prime}$ nitro- $N$-nitrosoguanidine; PKS, polyketide synthase; Rho, rhodinose; Rhn, rhodosamine.
}

(Fig. 1), is in clinical use to a limited extent as an anticancer agent for haematological malignancies. Aclarubicin was first described in 1975 as a product of Streptomyces galilaeus by Oki et al. (1975). The aglycone of aclarubicin is aklavinone (Akv), a common intermediate in the biosynthesis of several anthracyclines, and the attached trisugar moiety consists of rhodosamine (Rhn)-2-deoxyfucose (dF)-cinerulose A. A number of other aclacinomycins, with varying sugar moieties, have been described in the course of the intense search for novel anticancer agents (Fujii \& Ebizuka, 1997; Torkkell et al., 2001; Ylihonko et al., 1994). The mixture of aclacinomycins found in S. galilaeus ATCC 


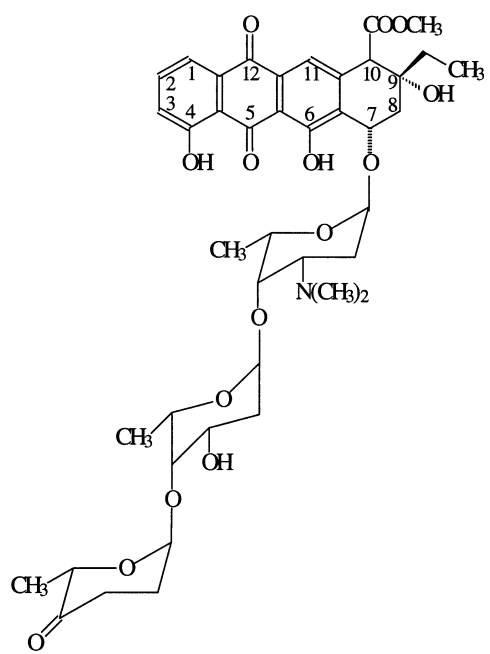

Fig. 1. Structure of aclacinomycin $A$.

31615 consists of three forms: aclacinomycin A, B and Y (AcmA, AcmB and AcmY) (Fig. 2a) that differ from each other in the third sugar residue.

Akv is synthesized via a polyketide pathway catalysed by a type II polyketide synthase (PKS), whereas the trisugar moiety is formed by stepwise addition of sugar residues generated by modification of a glucose molecule in a deoxyhexose pathway. Earlier methods, such as feeding of labelled precursors (Casey et al., 1978; Kitamura et al., 1981; Paulick et al., 1976), analysis of products from blocked mutants generated by UV irradiation or chemical mutagenesis (see reviews by Fujii \& Ebizuka, 1997; Grein, 1987; Hutchinson, 1997; Strohl et al., 1997) and biotransformations of late biosynthetic intermediates (Eckardt et al., 1985; Schumann et al., 1986; Wagner et al., 1984) have created a basis for understanding the biosynthetic steps involved. However, more detailed understanding was gained from molecular genetic studies on anthracyclines as well as other aromatic polyketides (see reviews by Fujii \& Ebizuka, 1997; Hutchinson, 1997; Strohl et al., 1997).

The biosynthetic pathway of Akv starts by the condensation of one propionate and nine acetates in a reaction series catalysed by the minimal PKS (Fig. 2a) (see reviews by Hutchinson, 1997; Strohl et al., 1997). Subsequently, ketoreduction, cyclization and oxygenation reactions in the PKS complex lead to a stable intermediate, aklanonic acid. Post-polyketide reactions, such as methylation of the carboxylic acid, cyclization and reduction, result in $\mathrm{Akv}$, which is ready for glycosylation. Three deoxysugars synthesized in S. galilaeus are attached to position C-7 of Akv in the following sequence: Rhn, dF and rhodinose (Rho) (resulting in AcmN). The attached Rho is rapidly converted by an extracellular oxidoreductase to cinerulose A (to form AcmA) and further to aculose (to form AcmY) (Yoshimoto et al., 1979). The third sugar residue is further converted to cinerulose $\mathrm{B}$ to form $\mathrm{AcmB}$, which is then taken into the bacterial cell and converted back to AcmA (Gräfe et al., 1988).

We have previously described an $S$. galilaeus ATCC 31615 mutant series blocked at different steps of the production of aclacinomycin A by $N$-methyl- $N^{\prime}$-nitro$\mathrm{N}$-nitrosoguanidine (NTG) mutagenization (Ylihonko et al., 1994). The mutants were characterized on the basis of their products and biotransformations. Cloning of the genes for aclacinomycins (Räty et al., 2000) and nogalamycin, another anthracycline (Torkkell et al., 2001, 1997; Ylihonko et al., 1996a, b), facilitated complementation of the mutants. Knowledge of the nature of the mutations clarifies the steps of the biosynthetic pathway for anthracyclines, provides tools for the analysis of gene functions and makes it possible to use the mutants rationally in combinatorial biosynthesis to create novel molecules.

Deoxysugars are in many cases essential for the activity of antibiotics and, thus, knowledge of their biosynthesis is important for rational design of novel active molecules. Therefore, in this study we focused on S. galilaeus strains with altered glycosylation patterns, aiming to identify the mutations leading to a deficient sugar moiety in aclacinomycins. Four strains included in previously described mutant series (Ylihonko et al., 1994), H026, $\mathrm{H} 038$, H039 and H054, and three additional mutants, H063, H065 (Räty et al., 2000) and H075 (DSM 11638) generated recently by NTG mutagenization, were investigated (Table 1, Fig. 2a). Complementation experiments with DNA fragments derived from $S$. galilaeus and other anthracycline producers have already given an idea of the biosynthetic genes blocked in strains H039, H054, H063 and H065 (Räty et al., 2000; Torkkell et al., 2001, 1997). Here, we report on a more thorough characterization of the $S$. galilaeus mutants to clarify the sequence of biosynthetic reactions of the sugar moiety. Mutated genes were revealed by complementation of the mutants with DNA fragments derived from S. galilaeus and further with PCR-amplified single genes. Moreover, corresponding genes from the mutants were amplified to demonstrate the mutation based on the DNA sequence. Finally, these results together with previous ones were used to confirm the mutations and to elucidate the biosynthetic pathway for aclacinomycin sugars, Rhn, dF and Rho.

\section{METHODS}

Bacterial strains and plasmids. Escherichia coli XL-1 Blue $\mathrm{MRF}^{\prime}$ (Stratagene), E. coli TOP10 (Invitrogen) and Streptomyces lividans TK24 (Kieser et al., 2000) were used as cloning hosts. S. galilaeus glycosylation mutants derived from $S$. galilaeus ATCC 31615 are described in Table 1 and Streptomyces plasmids used in this work are listed in Table 2.

Culture conditions and cloning procedures. For E. coli and Streptomyces strains the general culture conditions were as described by Sambrook et al. (1989) and Hopwood et al. (1985), respectively. For anthracycline production, the Streptomyces cultures were grown in E1 medium consisting of $20 \mathrm{~g}$ 


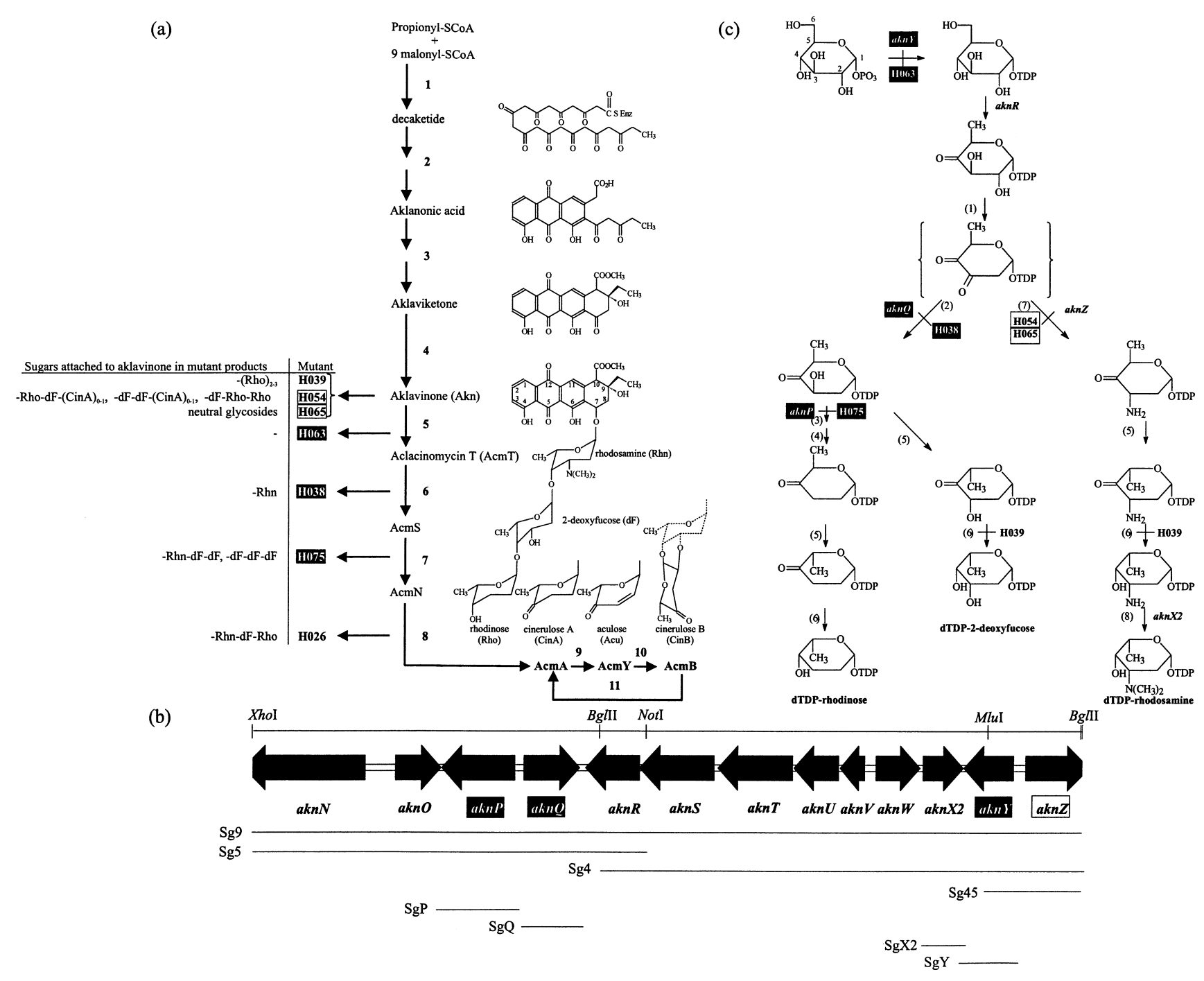

Fig. 2. (a) Proposed biosynthetic pathway of aclacinomycins $A, Y$ and $B(A c m A, A c m Y$ and $A c m B)$ produced in $S$. galilaeus ATCC 31615. The steps are as follows: 1, condensation; 2, ketoreduction, aromatization, cyclizations, oxygenation; 3, 10methylation, cyclization; 4, reduction; 5-7, glycosylation; 8-9, oxidoreduction; 10, reduction; 11, oxidoreduction. Products of S. galilaeus mutants with altered glycosylation patterns (H026, H038, H039, H054, H063, H065 and H075) are also presented. (b) Organization of the $\mathrm{Sg} 9$ gene cluster from S. galilaeus and the fragments used in the construction of expression plasmids. The putative functions of the gene products are described in Table 4. (c) Proposed pathways for dTDP-Rhn, dTDP-2-dF and dTDP-Rho in S. galilaeus. Probable enzymically catalysed steps are: (1) dehydration, (2) ketoreduction, (3) and (4) C-3 deoxygenation, (5) epimerization, (6) ketoreduction, (7) transamination and (8) aminomethylation. Genes from the Sg9 DNA fragment are presented beside the corresponding biosynthetic steps. Furthermore, mutants with altered glycosylation patterns are shown beside the mutated genes. Complemented mutants and complementing genes are indicated with boxes - black boxes indicate complete complementation and white boxes partial complementation.

glucose, $20 \mathrm{~g}$ soluble starch, $5 \mathrm{~g}$ Pharmamedia (Traders protein), $2.5 \mathrm{~g}$ yeast extract, $1 \mathrm{~g} \mathrm{~K}_{2} \mathrm{HPO}_{4}, 1 \mathrm{~g} \mathrm{MgSO} .7 \mathrm{H}_{2} \mathrm{O}$, $3 \mathrm{~g} \mathrm{NaCl}$ and $3 \mathrm{~g} \mathrm{CaCO}_{3}$ in 1 litre of tap water ( $\mathrm{pH} 7 \cdot 5$ ) (Ylihonko et al., 1994). For other purposes ISP4 agar plates (Difco) and TSB medium (Tryptone Soya Broth, Oxoid) were used. The plasmid-carrying strains were grown in the presence of $10 \mu \mathrm{g}$ thiostrepton $\mathrm{ml}^{-1}$ in liquid medium and $50 \mu \mathrm{g} \mathrm{ml}^{-1}$ in solid medium.

DNA isolation and manipulation in E. coli and Streptomyces strains were carried out by standard procedures (Hopwood et al., 1985; Sambrook et al., 1989). All Streptomyces strains were transformed by standard methods (Hopwood et al., 1985) with minor modifications (Ylihonko et al., 1996a). The DNA propagated in E. coli was cloned in pIJE486 and introduced into S. lividans TK24 and further into H039, which is easier to transform than the other $S$. galilaeus strains. Subsequently, DNA isolated from $\mathrm{H} 039$ was introduced into the other $S$. galilaeus mutant strains in question.

PCR. For expression constructs, genes $a k n P, a k n Q, a k n Y$ and aknX2 from $S$. galilaeus were amplified separately by PCR, 
Table 1. S. galilaeus mutants used in this work, plasmids which complement them and deduced mutated genes

\begin{tabular}{|c|c|c|c|c|c|}
\hline Mutant & Characteristic products & Reference & Complementing plasmids & Reference & Mutated gene \\
\hline H026 & Akv-Rhn-dF-Rho & Ylihonko et al. (1994) & - & & Oxidoreductase \\
\hline H038 & Akv-Rhn & Ylihonko et al. (1994) & pSgs9, pSgs5, pSgsQ & This work & $\begin{array}{l}\text { dTDP-hexose 3-ketoreductase } \\
(a k n Q)\end{array}$ \\
\hline H039 & $\mathrm{Akv}-(\mathrm{Rho})_{2-3}$ & Ylihonko et al. (1994) & pSYE36*† & Torkkell et al. (1997) & $\begin{array}{l}\text { dTDP-4-keto-6-deoxyhexose } \\
\text { reductase }\end{array}$ \\
\hline \multirow[t]{3}{*}{ H054 } & Akv-Rho-dF-(CinA $)_{0-1}$ & Ylihonko et al. (1994) & pSgs $4 *, p S g s 44^{*}$ & Räty et al. (2000) & Aminotransferase $(a k n Z)$ \\
\hline & $\mathrm{Akv}-\mathrm{dF}-\mathrm{dF}-(\mathrm{CinA})_{0-1}$ & & pSY61キ & Torkkell (2001) & \\
\hline & Akv-dF-Rho-Rho & & pSgs9*, pSgs $45^{*}$ & This work & \\
\hline \multirow[t]{2}{*}{ H063 } & Akv & Räty et al. (2000) & pSgs4, pSgs44 & Räty et al. (2000) & dTDP-glucose 1-synthase $(a k n Y)$ \\
\hline & & & pSgs9, pSgsY & This work & \\
\hline \multirow[t]{3}{*}{ H065 } & Akv with neutral glycosides & Räty et al. (2000) & pSgs $4 *, p S g s 44 *$ & Räty et al. (2000) & Aminotransferase $(a k n Z)$ \\
\hline & & & pSY61‡ & Torkkell (2001) & \\
\hline & & & pSgs9*, pSgs $45^{*}$ & This work & \\
\hline H075 & Akv-Rhn-dF-dF, Akv-dF-dF-dF & Ylihonko et al. (1999) & pSgs9, pSgs5, pSgsP & This work & dTDP-hexose 3-dehydratase $(a k n P)$ \\
\hline
\end{tabular}

"Partial complementation.

† Genes for dTDP-hexose 3,5-epimerase $(\operatorname{snog} F)$ and dTDP-4-keto-6-deoxyhexose reductase (snogG) from S. nogalater nogalamycin cluster.

$\ddagger$ Genes for an aminomethylase $(\operatorname{snog} A)$, a dTDP-glucose-synthase (snogJ) and an aminotransferase (snogI) from $S$. nogalater nogalamycin cluster. 
Table 2. Streptomyces plasmids used in this work

\begin{tabular}{|c|c|c|}
\hline Plasmid & Characteristics* & Source or reference \\
\hline pIJ486 & Streptomyces cloning vector & Ward et al. (1986) \\
\hline pIJE486 & ermE promoter (Bibb et al., 1985) cloned into the polylinker of pIJ486 & Ylihonko et al. (1996b) \\
\hline pSgs45 & Sg45 fragment from $S$. galilaeus cloned into pIJE486; genes aknY and $(Z)$ & Räty et al. (2000) \\
\hline pSgs5 & $\begin{array}{l}\text { Sg5 fragment from } S \text {. galilaeus (Räty et al., 2000) cloned into XbaI/HindIII-digested pIJE486; } \\
\text { genes } a k n(N), O, P, Q \text { and } R\end{array}$ & This work \\
\hline pSgs9 & $\begin{array}{l}\text { Sg9 fragment from } S . \text { galilaeus cloned into XbaI/HindIII-digested pIJE486; genes akn }(N) \text {, } \\
\text { O, } P, Q, R, S, T, U, V, W, X 2, Y,(Z)\end{array}$ & This work \\
\hline pSgsP & $\begin{array}{l}\text { PCR-amplified } a k n P \text { in fragment SgP from } S . \text { galilaeus cloned into XbaI/HindIII-digested } \\
\text { pIJE486 }\end{array}$ & This work \\
\hline pSgsQ & $\begin{array}{l}\text { PCR-amplified } a k n Q \text { in fragment SgQ from S. galilaeus cloned into XbaI/HindIII-digested } \\
\text { pIJE486 }\end{array}$ & This work \\
\hline pSgsX2 & $\begin{array}{l}\text { PCR-amplified aknX2 in fragment SgX2 from } S \text {. galilaeus cloned into XbaI/HindIII-digested } \\
\text { pIJE486 }\end{array}$ & This work \\
\hline pSgsY & $\begin{array}{l}\text { PCR-amplified } a k n Y \text { in fragment SgY from S. galilaeus cloned into XbaI/HindIII-digested } \\
\text { pIJE486 }\end{array}$ & This work \\
\hline
\end{tabular}

*Putative functions of the gene products are described in Table 4.

Table 3. $P C R$ primers used in amplification of genes $a k n P, a k n Q, a k n Y$ and $a k n X 2$

\begin{tabular}{|c|c|c|c|}
\hline Gene & Sequence $\left(5^{\prime}-\mathbf{3}^{\prime}\right)$ & $\begin{array}{l}\text { Portion of } \\
\text { the gene }\end{array}$ & RE site* \\
\hline \multirow[t]{2}{*}{$a k n P$} & TCTAG ATCCTTACGGAGGGACGGC & $5^{\prime}$ & $X b a \mathrm{I}$ \\
\hline & AAGCTT GTGTTCGACCGGATGATC & $3^{\prime}$ & HindIII \\
\hline \multirow[t]{2}{*}{$a k n Q$} & 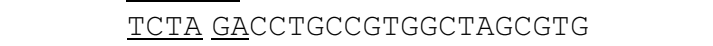 & $5^{\prime}$ & $X b a \mathrm{I}$ \\
\hline & AAGCTT CCTTCTCTCGTCGTGCGG & $3^{\prime}$ & HindIII \\
\hline \multirow[t]{2}{*}{$a k n Y$} & TCTAGA TTGCTGCCGAGCGAATCC & $5^{\prime}$ & $X b a \mathrm{I}$ \\
\hline & AAGCTTCATATG CGCGGTCTTTTCGTCGGTGTTCGC & $3^{\prime}$ & HindIII, NdeI \\
\hline \multirow[t]{2}{*}{$a k n X 2$} & TCTAGA GCCGACGGAGGGAACAGAC & $5^{\prime}$ & $X b a \mathrm{I}$ \\
\hline & AAGCTT ACCTTCCTCCGGCTCAGC & $3^{\prime}$ & HindIII \\
\hline
\end{tabular}

* Restriction endonuclease recognition site (underlined) inserted within the primer sequence.

using the primers shown in Table 3. Furthermore, the postulated mutated gene was amplified from the corresponding mutant strain. PCR was carried out with 25 pmol each oligonucleotide primer, 10-15 ng of the strain's chromosomal DNA, $0.2 \mathrm{mM}$ each dNTP, 2\% DMSO and $0.7 \mathrm{U}$ DNA polymerase DyNAzyme EXT (Finnzymes) or Pfu (Promega). The template was initially denatured by heating at $96{ }^{\circ} \mathrm{C}$ for $3 \mathrm{~min}$, followed by 30 cycles of amplification, i.e. denaturation at $94^{\circ} \mathrm{C}$ for $30 \mathrm{~s}$, annealing at $60-64{ }^{\circ} \mathrm{C}$ for $1 \mathrm{~min}$ and extension at $73{ }^{\circ} \mathrm{C}$ for 1 min $15 \mathrm{~s}$ (with DyNAzyme EXT) or for 2 min $45 \mathrm{~s}$ (with Pfu). The reaction was completed with extension for $8.5 \mathrm{~min}$. When Pfu was used, the 3' A-overhangs were generated by additional extension at $73{ }^{\circ} \mathrm{C}$ for $10 \mathrm{~min}$ with $0.7 \mathrm{U}$ Dynazyme II DNA polymerase (Finnzymes). The PCR products obtained were cloned in E. coli, using the TOPO TA Cloning Kit (Invitrogen) according to the manufacturer's instructions.

Sequencing and sequence analysis. Amplified genes were verified by sequencing. Plasmids were isolated by alkaline lysis and further purified by the Qiagen gel extraction kit. DNA sequencing was performed by an automatic ABI DNA sequencer (Perkin-Elmer) according to the manufacturer's instructions. Sequence analysis was carried out using the GCG
(Version 8; Genetics Computer Group, Madison, Wisconsin, USA) and Vector NTI Suite (Version 6.0) sequence analysis software packages. The deduced gene products were analysed by using the network service programs BLASTP and CD-search provided by the US National Center for Biotechnology Information (NCBI, http://www.ncbi.nlm.nih.gov/).

Expression constructs and complementations. Overlapping S. galilaeus DNA fragments $\mathrm{Sg} 4$ and $\mathrm{Sg} 5$ from plasmids pSgc4 and pSgc5 (Räty et al., 2000) were combined to get the contiguous DNA fragment $\mathrm{Sg} 9$ (Table 4, Fig. 2b). First, Xhol/NotI-digested Sg5 was cloned into pSL1190 to give pSgc5SL. Second, the NotI-BglII portion of Sg4 from NotI/ PstI-digested pSgc4 was cloned into pSgc5SL to give Sg9 in pSgc9SL. Subsequently, the $\mathrm{Sg} 9$ fragment from $\mathrm{XbaI} / \mathrm{HindIII}-$ digested pSgc9SL was cloned into pIJE486 and the plasmid was designated $\mathrm{pSgs} 9$. Also, XbaI/HindIII-digested Sg5 from pSgc5SL was cloned in pIJE486 to give expression construct pSgs5. Both pSgs5 and pSgs9 were first introduced into S. lividans TK24 and further into S. galilaeus H039, and subsequently into all other $S$. galilaeus mutants with altered glycosylation patterns: H026, H038, H054, H063, H065 and $\mathrm{H} 075$.

Genes $a k n P, a k n Q, a k n Y$ and $a k n X 2$ in DNA fragments $\mathrm{SgP}$, 
Table 4. Putative functions of $\mathrm{Sg} 9$ gene products (Räty et al., 2000)

\begin{tabular}{|lrl|}
\hline $\begin{array}{l}\text { Gene } \\
\text { product }\end{array}$ & $\begin{array}{c}\text { Amino } \\
\text { acids }\end{array}$ & \multicolumn{1}{c|}{ Function } \\
\hline AknN & $>661$ & Unknown \\
AknO & 272 & Activator \\
AknP & 434 & dTDP-hexose 3-dehydratase \\
AknQ & 329 & dTDP-hexose 3-ketoreductase \\
AknR & 323 & dTDP-glucose 4,6-dehydratase \\
AknS & 443 & Glycosyltransferase \\
AknT & 443 & Unknown \\
AknU & 267 & Aklaviketone reductase \\
AknV & 144 & Unknown \\
AknW & 259 & Cyclase \\
AknX2 & 238 & Aminomethylase \\
AknY & 291 & dTDP-glucose 1-synthase \\
AknZ & $>340$ & Aminotransferase \\
\hline
\end{tabular}

SgQ, SgY and SgX2, respectively, were amplified by PCR from wild-type $S$. galilaeus and cloned from pCR2.1-TOPO vectors in pIJE486 under the control of the ermE promoter using $\mathrm{XbaI}$ and HindIII restriction sites inserted within primer sequences. Plasmids pSgsP, pSgsQ, pSgsY and $\mathrm{pSgsX} 2$ were then introduced, in addition to TK24 and H039, into $S$. galilaeus mutants thought to contain mutations in the corresponding genes: pSgsP into H075, pSgsQ into H038, pSgsY into H063 and pSgsX2 into H054 and H065.

Detection of anthracycline metabolites. The strains were cultivated in $30 \mathrm{ml} \mathrm{E} 1$ medium for 4-5 days to determine the nature and amounts of anthracycline metabolites. A $500 \mu \mathrm{l}$ sample of E1 culture was adjusted to $\mathrm{pH} 7 \cdot 0$ by addition of $500 \mu \mathrm{l} 1 \mathrm{M}$ potassium phosphate buffer and cells were subsequently extracted with $250 \mu \mathrm{l}$ methanol and $250 \mu \mathrm{l}$ toluene. The toluene layer was concentrated and spotted in $10 \mu \mathrm{l}$ toluene on a precoated Kieselgel $60 \mathrm{~F}_{254}$ glass plate (Merck) developed with toluene/ethyl acetate/methanol/formic acid (50:50:15:3, by vol.). Whenever necessary, metabolites were also detected by HPLC on a Hewlett Packard 1100 series chromatograph equipped with a LiCHroCART RP-18e column (Purospher, $3 \mu \mathrm{m}, 4.0 \times 55 \mathrm{~mm}$ ) and a diode array detector. The compounds were separated using $0 \cdot 1 \%$ formic acid and $0 \cdot 1 \%$ formic acid in $\mathrm{MeCN}$ with a gradient from 70 to $2 \%$ formic acid. The flow rate was $1 \mathrm{ml} \mathrm{min}^{-1}$, and detection was done at 254 and $430 \mathrm{~nm}$. The structures of the anthracyclines were deduced from $R_{\mathrm{F}}$ values, retention times and UV/VIS-spectra by comparing with references.

\section{RESULTS}

DNA fragment Sg9 (Fig. 2b, Table 4), which contains genes for the sugar moiety of aclacinomycins, was introduced into pSgs9 into S. galilaeus mutants H026, H038, H039, H054, H063, H065 and H075 with altered glycosylation patterns (Fig. 2a, Table 1) to study its effect on anthracycline metabolites of the mutants. Complemented strains were further studied by introducing expression constructs containing single genes. The production profiles of the wild-type $S$. galilaeus, the investigated mutant and the plasmid-carrying mutant were analysed on TLC and further by HPLC to note any differences. Mutation in the gene that causes the mutant phenotype was further demonstrated by identifying the error in the DNA sequence. Deduced mutations of all the strains together with their products and plasmids complementing them are presented in Table 1. Furthermore, a hypothetical biosynthetic pathway for aclacinomycin sugars (Fig. 2c) was deduced from the data obtained in this work and previous results (Räty et al., 2000).

\section{Complementation of the mutations in S. galilaeus strains with a set of genes for aclacinomycins (Sg9)}

Fragments Sg4 and Sg5, obtained from S. galilaeus gene libraries, were demonstrated previously to contain genes for the deoxyhexose pathway for aclacinomycins (Räty et al., 2000). Here, these two fragments were combined to give pSgs9 in pIJE486, carrying a $14.8 \mathrm{~kb}$ contiguous DNA sequence for aclacinomycin biosynthesis. Plasmid pSgs9 was introduced into $S$. galilaeus mutants. Genes in the Sg9 fragment complemented the mutation in $\mathrm{H} 063$ completely and in H054 and H065 partially, as expected, because the mutations were earlier complemented similarly by the introduction of pSgs4 (Räty et al., 2000). In addition, mutations in $\mathrm{H} 038$ and $\mathrm{H} 075$ were fully complemented by the introduction of plasmid $\mathrm{pSgs} 9$ to restore the wild-type production profile. In contrast, introduction of pSgs9 into mutants H026 and H039 did not have any effect on anthracycline metabolites of the strains.

\section{Mutations in S. galilaeus strains}

Mutations in strains H038, H054, H063, H065 and $\mathrm{H} 075$, complemented by the introduction of plasmid pSgs9, were studied more closely. The gene that was concluded to be responsible for the complementation of the corresponding mutant, as deduced from the putative gene product and production profile of the mutant, was amplified by PCR from the wild-type S. galilaeus, sequenced and expressed in the mutant. Furthermore, the corresponding gene was amplified by PCR from the mutant strain and its mutation was analysed by comparing its DNA sequence to that of the wild-type S. galilaeus.

H038. The endogenous product of $\mathrm{H} 038$ is AcmT, an intermediate of aclacinomycin A biosynthesis, with Rhn as its only sugar. The mutation in $\mathrm{H} 038$ was thus concluded to be in a gene which participates in the biosynthesis or transfer of both $\mathrm{dF}$ and Rho. In addition to pSgs9, introduction of its subclone pSgs5 into H038 restored wild-type production in the mutant. Thus, based on the proposed hypothetical pathway, aknQ, encoding dTDP-hexose 3-ketoreductase, was the most probable candidate for the mutated gene. Consistently, expression of $a k n Q$ in $\mathrm{H} 038$ restored wild-type production in the mutant.

AknQ has significant amino acid homology to several dTDP-hexose 3-ketoreductases from antibiotic clusters 
containing 2-deoxyhexose sugars. Recently, in vitro studies of AknQ homologues Gra Orf26 (identity/similarity $48 / 61 \%$ ) from the Streptomyces violaceoruber Tü22 granaticin cluster (Ichinose et al., 1998) and Tü99 Orf11 $(51 / 64 \%)$ from the Streptomyces antibioticus Tü99 oleandomycin cluster (Draeger et al., 1999) illustrated their participation in the 2-deoxygenation step (Draeger et al., 1999). These enzymes were shown to operate in concert with dTDP-4-keto-deoxyglucose 2,3dehydratases by stabilizing their labile 2-deoxygenated product through 3-ketoreduction.

Sequencing of the mutated $a k n Q$ from $\mathrm{H} 038$ revealed a G-to-A transition at nucleotide 524, causing a glycineto-aspartate substitution at amino acid 175 . This glycine is conserved in the C-terminal $\alpha / \beta$ domain of the GFO_IDH_MocA oxidoreductase family (pfam02894) and, furthermore, it is the first in a set of four identical amino acids, GGAL, in AknQ and its closest homologues. This missense mutation prevents the biosynthesis of both Rho and $\mathrm{dF}$ in $\mathrm{H} 038$ and was complemented by the expression of $a k n Q$.

H063. Mutant strain H063 accumulates Akv. This indicates the mutation to be in a gene catalysing one of the first steps in the biosynthetic pathway of deoxyhexoses or in a glycosyltransferase. Recently, the mutation in H063 was complemented with pSgs44, carrying genes only for cyclase $(a k n W)$, aminomethylase (aknX2), dTDP-glucose-1-synthase $(a k n Y)$ and partial aminotransferase (aknZ) (Räty et al., 2000). Since dTDPglucose-1-synthase catalyses the well-established first step of the deoxyhexose pathway, the mutation was suggested to be in gene aknY. Here, as expected, expression of PCR-amplified aknY in $\mathrm{H} 063$ complemented the mutation in the strain.

The DNA sequence of aknY in S. galilaeus $\mathrm{H} 063$ demonstrated a C-to-T transition mutation at position 53 , resulting in a threonine-to-isoleucine change at amino acid 18 in the conserved nucleotidyl transferase domain (pfam00483). The mutation prevents the biosynthesis of deoxyhexoses completely, because no detectable amount of glycosidic metabolites was recovered from the culture broth of $\mathrm{H} 063$, but complementation with $a k n Y$ was complete.

H075. In addition to its main product Akv-Rhn-dF-dF, $\mathrm{H} 075$ produces minor amounts of Akv-dF-dF-dF. Thus, the mutation in $\mathrm{H} 075$ would be predicted to be in a gene taking part in the biosynthesis or transfer of Rho. Very recently, dTDP-hexose 3-dehydratase, encoded by $r d m I$, from rhodomycin-producing Streptomyces purpurascens ATCC 25489, was revealed to complement the mutation in strain H075 (data not shown). Here, plasmid pSgs5, which includes aknP for dTDP-hexose 3dehydratase, also complemented mutation in H075. Consistently, expression of $a k n P$ restored the wildtype production profile in $\mathrm{H} 075$.

AknP, a polypeptide of 434 aa, resembles several putative 3-dehydratases involved in the C-3 deoxygenation step in the deoxysugar biosynthesis of antibiotics. The closest homologues are UrdQ (identity/similarity
$72 / 81 \%$ ) from the Streptomyces fradiae Tü2717 urdamycin biosynthetic gene cluster (Hoffmeister et al., 2000), LanQ (71/81\%) from the Streptomyces cyanogenus S136 landomycin cluster (Westrich et al., 1999) and the gra-ORF23 product $(71 / 82 \%)$ from the Streptomyces violaceoruber Tü22 granaticin cluster (Ichinose et al., 1998; Tornus \& Floss, 2001). Moreover, AknP is similar to CDP-4-keto-6-deoxyglucose-3-dehydratases $\mathrm{RfbH}$ and AscC $\left(\mathrm{E}_{1}\right)$ participating in the deoxysugar biosynthesis of the O-antigen in Yersinia pseudotuberculosis (Kessler et al., 1993; Lei et al., 1995). AscC and $\mathrm{RfbH}$ are pyridoxamine $5^{\prime}$-phosphate (PMP)-dependent iron-sulphur-containing enzymes, which catalyse the $\mathrm{C}-\mathrm{O}$ bond cleavage at $\mathrm{C}-3$ of the substrate, leading to the formation of 3,6-dideoxyhexose. All abovementioned 3-dehydratases share the $\mathrm{Gx}_{3} \mathrm{Dx}_{7} \mathrm{Ax}_{8} \mathrm{EDx}_{10}$ $\mathrm{Gx}_{3} \mathrm{Gx}_{13} \mathrm{Hx}_{4} \mathrm{GEGGx}_{19} \mathrm{Gx}_{2} \mathrm{Cx}_{1} \mathrm{Cx}_{7} \mathrm{C}$ motif, which is similar to the secondary metabolic aminotransferase family (SMAT) (Piepersberg, 1994). However, 3-dehydratases differ from their proposed ancestors, pyridoxal 5 '-phosphate-dependent aminotransferases, in having a conserved histidine residue at the active site, instead of lysine, indicating dependence of 3-dehydratases on PMP (Lei et al., 1995). In addition, iron-sulphur-binding cysteine residues are not found in the aminotransferases.

Sequencing of the mutated aknP from $\mathrm{H} 075$ revealed a G-to-A transition at codon 245 that changes tryptophan (TGG) to a stop codon (TGA). The mutation precedes the last conserved glycine in the 3-dehydratase motif. As is typical of nonsense mutations, 3-dehydratase enzyme activity is fully missing in $\mathrm{H} 075$, resulting in products without Rho.

H054 and H065. Both H054 and H065, whose production profiles are not the same but are very similar, accumulate anthracyclines consisting of only neutral sugars, thus being deficient in the biosynthesis or transfer of the aminosugar Rhn. Instead, a different combination of Rho, dF and cinerulose $\mathrm{A}$, either as di- or trisugar moieties, is produced. In an earlier work, mutations in H054 and H065 were partially complemented with plasmid pSgs 44 , carrying genes for a cyclase $(a k n W)$, an aminomethylase $(a k n X 2)$, a dTDP-glucose-1-synthase $(a k n Y)$ and a part of an aminotransferase lacking the $\mathrm{C}$ terminus (aknZ) (Räty et al., 2000). Of these genes, $a k n X 2$ and $a k n Z$ participate in the biosynthesis of $\mathrm{Rhn}$ solely. The incompleteness of gene aknZ led us to the misassumption that the mutated gene in strains H054 and H065 is the aminomethylase (aknX2). In this study, however, the introduction of plasmid pSgsX2 carrying $a k n X 2$ into mutants $\mathrm{H} 054$ and $\mathrm{H} 065$ did not alter their production profiles. Furthermore, there were no nucleotide changes in the sequence of $a k n X 2$ in either mutant when compared to that of the wild-type gene.

According to our results, the complementing gene has to be the one encoding aminotransferase, although it is only partial in plasmid pSgs44. Therefore, the expression construct pSgs45 (Räty et al., 2000) (Table 2, Fig. $2 \mathrm{~b})$, containing partial $a k n Z$ with $a k n Y$, which encodes dTDP-glucose-1-synthase, was introduced into H054 and H065. Both mutants were partly complemented, as 
was noted with pSgs 44 . Thus, the truncated AknZ seems to be capable of partial complementation of the mutations in $\mathrm{H} 054$ and H065. The length of the product of partially cloned $a k n Z$ is 340 aa, whereas a corresponding gene, aclZ, from another aclacinomycin-producing $S$. galilaeus (mutant strain 3AR-33, which is derived from strain ATCC 31133) encodes a polypeptide of 369 aa $(96 / 97 \%$; GenBank, accession no. AB008466). The lack of about 30 aa in AknZ leads to weakened, but not abolished, aminotransferase activity, enabling partial complementation of mutations in $\mathrm{H} 054$ and H065.

\section{DISCUSSION}

Because of its trisugar moiety with different sugar residues attached to an $\mathrm{Akv}$ core, aclacinomycin is an ideal target for studies on deoxyhexose biosynthesis. Mutations in deoxyhexose genes result in loss of one or more of the naturally synthesized deoxysugars. Here, single point mutations were shown to be responsible for blocking the biosynthesis of aclacinomycin sugars in mutants with altered glycosylation patterns. Knowledge of the nature of the mutations will facilitate rational use of these mutants in future and elucidate the proposed hypothetical biosynthetic pathway (Fig. 2c) for the deoxysugars of aclacinomycins (Räty et al., 2000).

Strain H063, accumulating Akv, was shown to contain a missense mutation in the putative dTDP-glucose-1synthase gene $a k n Y$. dTDP-glucose-1-synthase adds a deoxynucleotide to a phosphorylated glucose, catalysing the common and well-established first step in the deoxyhexose pathway. Deficiency in this enzyme explains the lack of any deoxysugars in $\mathrm{H} 063$ products. In addition, the complementation of $\mathrm{H} 063$ with aknY strengthens the previous assignation of AknY function.

In strain $\mathrm{H} 038$, a missense mutation in the dTDP-hexose 3 -ketoreductase gene $a k n Q$ was seen to result in accumulation of AcmT, with Rhn as its only sugar. This strengthens the previous assumption that biosynthetic routes of Rho and $\mathrm{dF}$ diverge from that of Rhn in the 2-deoxygenation step (Räty et al., 2000). In vitro studies with purified enzymes have clarified the mechanism of the 2-deoxygenation step of neutral deoxyhexoses (Chen et al., 1999; Draeger et al., 1999). It was illustrated with enzymes derived from the granaticin and oleandomycin clusters that 2,3-dehydratase in concert with 3-ketoreductase converts dTDP-4-keto-6-deoxy-D-glucose into dTDP-4-keto-2,6-dideoxy-D-glucose (Draeger et al., 1999). We assume that 3-ketoreduction in the deoxysugar biosynthetic pathway of aclacinomycin results similarly in dTDP-4-keto-2,6-dideoxy-D-glucose with the equatorial (3R) hydroxyl, although 3-ketoreduction in mycarose biosynthesis has been shown to lead to opposite stereochemistry (Chen et al., 1999). This is because AknQ is more similar to 3-ketoreductases Gra Orf26 and Tü99 Orf11 derived from the granaticin and oleandomycin biosynthetic clusters, respectively. Furthermore, both AknQ and Gra Orf26 are involved in the biosynthesis of Rho.
The mutation in H075, which accumulates aclacinomycins without Rho or its derivatives, was shown to be a nonsense mutation in the gene encoding dTDP-hexose 3-dehydratase, aknP. This is in accordance with the previous assumption that the biosynthesis of Rho differs from that of $\mathrm{dF}$ in the 3-deoxygenation step (Räty et al., 2000).

Mutants H054 and H065, which accumulate only aclacinomycins with neutral sugars, were shown to be deficient in the aminotransferase AknZ. Also, complementation experiments with genes derived from the nogalamycin biosynthetic cluster support this conclusion (Torkkell, 2001). Mutations in H054 and H065 were complemented by snogI, encoding a 370 aa aminotransferase for nogalamine, a sugar moiety of nogalamycin. The absence of approximately 30 aa in AknZ does not abolish all of its catalytic activity, whilst it explains why the mutations were only partially complemented. As discussed above, the biosynthetic pathway of Rhn differs from that of Rho and $\mathrm{dF}$ in the 2-deoxygenation step. Instead of 3-ketoreductase, the product of dTDP-4-keto-6-deoxyglucose 2,3-dehydratase is probably stabilized by an aminotransferase (AknZ), as has been suggested for other aminosugars (Draeger et al., 1999; Olano et al., 1999).

Apart from the above-mentioned mutants complemented with akn genes, the mutation in strain $\mathrm{H} 039$ has been complemented partially with a dTDP-4-keto6-deoxyhexose reductase gene, snogG, derived from the nogalamycin biosynthetic cluster (Torkkell et al., 2001, 1997). Since the sugar moieties of aclacinomycins produced by $\mathrm{H} 039$ consist of Rho residues only, inactivation of 4-ketoreductase seems to prevent the biosynthesis of both Rhn and dF. Thus, according to the proposed pathway, the same 4-ketoreductase catalyses the reduction of both $\mathrm{dF}$ and Rhn. Very recently, a homologue of snogG, aknM, was also found in the S. galilaeus aclacinomycin cluster (Räty et al., 2002). However, $a k n M$ is only partially in the cloned region and did not complement the mutation in strain H039 (data not shown). Expression of another dTDP-4-keto6-deoxyhexose reductase gene from the nogalamycin biosynthetic cluster, snogC, producing the inverted (4S) configuration, resulted in the production of Akv-4'epi-dF in H039 (Torkkell et al., 2001). SnogC probably acts on the 2-deoxygenated sugar dTDP-4-keto-2,6dideoxy-D-glucose in aclacinomycin deoxyhexose biosynthesis, preventing the 3-deoxygenation step in the biosynthesis of Rho, but allowing epimerization of the $\mathrm{dF}$ route. Epimerization might also precede 3deoxygenation and would thus be a common step in the biosynthesis of Rho and dF. However, the synthesis of $\mathrm{D}-\mathrm{Rho}$ in $S$. fradiae mutant $\mathrm{RN}-435$, which produces urdamycin $M$, implies that in Rho biosynthesis 3-deoxygenation occurs prior to 5-epimerization (Hoffmeister et al., 2000).

The mutation in $\mathrm{H} 026$ has not yet been complemented. However, the production of Akv-Rhn-dF-Rho strongly implies that $\mathrm{H} 026$ is deficient in an oxidoreductase 
which converts attached Rho into cinerulose A (resulting in $\mathrm{AcmA}$ ) and further into L-aculose (AcmY) (Yoshimoto et al., 1979). This conclusion is supported by the capability of $\mathrm{H} 026$ to convert fed $\mathrm{AcmB}$ into AcmA, but not further into AcmY (Ylihonko et al., 1994).

The diversity of aclacinomycin glycosylation in $S$. galilaeus mutants implies loose substrate specificity of glycosyltransferases. Although Rhn appears only as the first sugar in aclacinomycins produced by the mutants, $\mathrm{dF}$ and Rho can be found in different combinations as first, second or third sugar. Furthermore, $4^{\prime}$-epi-dF was attached to Akv when the dTDP-4-keto-6-deoxyhexose reductase gene from the nogalamycin biosynthetic cluster, snogC, was expressed in the H039 mutant (Torkkell et al., 2001). Recently, relaxed specificity for both sugar co-substrates and alcohol substrates has been described for various glycosyltransferases (Aguirrezabalaga et al., 2000; Blanco et al., 2001; Hoffmeister et al., 2000; Tang \& McDaniel, 2001; Trefzer et al., 2001; Zhao et al., 1999). So far, two glycosyltransferases, AknK and AknS, have been cloned from the $S$. galilaeus aclacinomycin biosynthetic cluster (Räty et al., 2000, 2002). However, their individual function in sugar attachment has not been assigned, and since the whole biosynthetic cluster for aclacinomycins has not yet been cloned, we do not know whether they are involved in the transfer of one or more deoxysugars.

In the present work, we studied more closely the mutations behind the deficient glycosylation of aclacinomycins in S. galilaeus mutants. In each characterized mutant, a single point mutation in a deoxyhexose biosynthetic gene was responsible for abolished enzyme activity leading to the accumulation of products missing one or more of the inherently synthesized deoxysugars. Exact knowledge of the nature of the mutations enhances the usage and value of these mutants in the analysis of gene function and creation of novel compounds. In addition, the results strengthen the assignments of the $a k n$ gene products and enlighten the biosynthetic pathway for deoxyhexoses. These results also show that chemical mutagenization, despite its randomness, still offers a convenient tool to create single point mutations affecting only a specific biosynthetic gene, and that it can be used together with molecular biology to study the biosynthesis of different compounds and to learn more about features important to the catalytic activity of the enzymes.

\section{ACKNOWLEDGEMENTS}

This research was supported by the Academy of Finland and the National Technology Agency, Finland (TEKES). We thank Hilkka Salmén for comments on the English language in this paper.

\section{REFERENCES}

Aguirrezabalaga, I., Olano, C., Allende, N., Rodriguez, L., Braña, A. F., Méndez, C. \& Salas, J. A. (2000). Identification and expression of genes involved in biosynthesis of L-oleandrose and its intermediate L-olivose in the oleandomycin producer Streptomyces antibioticus. Antimicrob Agents Chemother 44, 12661275.

Bibb, M. J., Janssen, G. R. \& Ward, J. M. (1985). Cloning and analysis of the promoter region of the erythromycin resistance gene (ermE) of Streptomyces erythraeus. Gene 38, 215-226.

Blanco, G., Patallo, E. P., Braña, A. F., Trefzer, A., Bechthold, A., Rohr, J., Méndez, C. \& Salas, J. A. (2001). Identification of a sugar flexible glycosyltransferase from Streptomyces olivaceus, the producer of the antitumor polyketide elloramycin. Chem Biol 8, 253-263.

Casey, M. L., Paulick, R. C. \& Whitlock, H. W. (1978). Carbon-13 nuclear magnetic resonance study of the biosynthesis of daunomycin and islandicin. J Org Chem 43, 1627-1634.

Chen, H., Agnihotri, G., Guo, Z., Que, N. L. S., Chen, X. H. \& Liu, H.-w. (1999). Biosynthesis of mycarose: isolation and characterization of enzymes involved in the C-2 deoxygenation. J Am Chem Soc 121, 8124-8125.

Draeger, G., Park, S.-H. \& Floss, H. G. (1999). Mechanism of the 2deoxygenation step in the biosynthesis of the deoxyhexose moieties of the antibiotics granaticin and oleandomycin. J Am Chem Soc 121, 2611-2612.

Eckardt, K., Schumann, G., Gräfe, U., Ihn, W., Wagner, C., Fleck, W. F. \& Thrum, H. (1985). Preparation of labeled aklanonic acid and its bioconversion to anthracyclinones by mutants of Streptomyces griseus. J Antibiot 38, 1096-1097.

Fujii, I. \& Ebizuka, Y. (1997). Anthracycline biosynthesis in Streptomyces galilaeus. Chem Rev 97, 2511-2523.

Gräfe, U., Dornberger, K., Fleck, W. F. \& Freysoldt, C. (1988). Compartmentation of enzymes interconverting aclacinomycins in Streptomyces species AM 33352. J Basic Microbiol 28, 17-23.

Grein, A. (1987). Antitumor anthracyclines produced by Streptomyces peucetius. Adv Appl Microbiol 32, 203-214.

Hoffmeister, D., Ichinose, K., Domann, S. \& 9 other authors (2000). The NDP-sugar co-substrate concentration and the enzyme expression level influence the substrate specificity of glycosyltransferases: cloning and characterization of deoxysugar biosynthetic genes of the urdamycin biosynthetic gene cluster. Chem Biol 7, 821-831.

Hopwood, D. A., Bibb, M. J., Chater, K. F. \& 7 other authors (1985). Genetic Manipulation of Streptomyces: a Laboratory Manual. Norwich: John Innes Foundation.

Hutchinson, C. R. (1997). Biosynthetic studies of daunorubicin and tetracenomycin C. Chem Rev 97, 2525-2535.

Ichinose, K., Bedford, D. J., Tornus, D., Bechthold, A., Bibb, M. J., Revill, W. P., Floss, H. G. \& Hopwood, D. A. (1998). The granaticin biosynthetic gene cluster of Streptomyces violaceoruber Tü22: sequence analysis and expression in a heterologous host. Chem Biol 5, 647-659.

Kessler, A. C., Haase, A. \& Reeves, P. R. (1993). Molecular analysis of the 3,6-dideoxyhexose pathway genes of Yersinia pseudotuberculosis serogroup IIA. J Bacteriol 175, 1412-1422.

Kieser, T., Bibb, M. J., Buttner, M. J., Chater, K. F. \& Hopwood, D. A. (2000). Practical Streptomyces Genetics. Norwich: John Innes Foundation.

Kitamura, I., Tobe, H., Yoshimoto, A., Oki, T., Naganawa, H., Takeuchi, T. \& Umezawa, H. (1981). Biosynthesis of aklavinone and aclacinomycins. J Antibiot 34, 1498-1500.

Lei, Y., Ploux, O. \& Liu, H.-w. (1995). Mechanistic studies on CDP6-deoxy-L-threo-D-glycero-4-hexulose 3-dehydrase: identification of His-220 as the active-site base by chemical modification and site-directed mutagenesis. Biochemistry 34, 4643-4654. 
Oki, T., Matsuzawa, Y., Yoshimoto, A. \& 10 other authors (1975). New antitumor antibiotics, aclacinomycins A and B. J Antibiot $28,830-834$.

Olano, C., Lomovskaya, N., Fonstein, L., Roll, J. T. \& Hutchinson, C. R. (1999). A two-plasmid system for the glycosylation of polyketide antibiotics: bioconversion of $\varepsilon$-rhodomycinone to rhodomycin D. Chem Biol 6, 845-855.

Paulick, R. C., Casey, M. L. \& Whitlock, H. W. (1976). A ${ }^{13} \mathrm{C}$ nuclear magnetic resonance study of the biosynthesis of daunomycin from ${ }^{13} \mathrm{CH}_{3}{ }^{13} \mathrm{CO}_{2} \mathrm{Na}$. J Am Chem Soc 98, 3370-3371.

Piepersberg, W. (1994). Pathway engineering in secondary metabolite-producing actinomycetes. Crit Rev Biotechnol 14, 251-285.

Räty, K., Kunnari, T., Hakala, J., Mäntsälä, P. \& Ylihonko, K. (2000). A gene cluster from Streptomyces galilaeus involved in glycosylation of aclarubicin. Mol Gen Genet 264, 164-172.

Räty, K., Kantola, J., Hautala, A., Hakala, J., Ylihonko, K. \& Mäntsälä, P. (2002). Cloning and characterization of Streptomyces galilaeus aclacinomycins polyketide synthase (PKS) cluster. Gene 293, 115-122.

Sambrook, J., Fritsch, E. F. \& Maniatis, T. (1989). Molecular Cloning: a Laboratory Manual, 2nd edn. Cold Spring Harbor, NY : Cold Spring Harbor Laboratory.

Schumann, G., Stengel, C., Eckardt, K. \& Ihn, W. (1986). Biotransformation of aklanonic acid by blocked mutants of anthracycline-producing strains of Streptomyces galilaeus and Streptomyces peucetius. J Basic Microbiol 26, 249-255.

Strohl, W. R., Dickens, M. L., Rajgarhia, V. B., Woo, A. J. \& Priestley, N. D. (1997). Anthracyclines. In Biotechnology of Antibiotics, pp. 577-657. Edited by W. R. Strohl. New York: Marcel Dekker Inc.

Tang, L. \& McDaniel, R. (2001). Construction of desosamine containing polyketide libraries using a glycosyltransferase with broad substrate specificity. Chem Biol 8, 547-555.

Torkkell, S. (2001). Anthracycline antibiotics: biosynthetic pathway and molecular genetics of nogalamycin, a product of Streptomyces nogalater. PhD thesis, University of Turku, Finland.

Torkkell, S., Ylihonko, K., Hakala, J., Skurnik, M. \& Mäntsälä, P. (1997). Characterization of Streptomyces nogalater genes encoding enzymes involved in glycosylation steps in nogalamycin biosynthesis. Mol Gen Genet 256, 203-209.

Torkkell, S., Kunnari, T., Palmu, K., Mäntsälä, P., Hakala, J. \& Ylihonko, K. (2001). The entire nogalamycin biosynthetic gene cluster of Streptomyces nogalater: characterization of a $20-\mathrm{kb}$ DNA region and generation of hybrid structures. Mol Genet Genomics 266, 276-288.

Tornus, D. \& Floss, H. G. (2001). Identification of four genes from the granaticin biosynthetic gene cluster of Streptomyces vio- laceoruber Tü22 involved in the biosynthesis of L-rhodinose. J Antibiot 54, 91-101.

Trefzer, A., Fischer, C., Stockert, S., Westrich, L., Künzel, E., Girreser, U., Rohr, J. \& Bechthold, A. (2001). Elucidation of the function of two glycosyltransferase genes (lanGT1 and lanGT4) involved in landomycin biosynthesis and generation of new oligosaccharide antibiotics. Chem Biol 8, 1239-1252.

Wagner, C., Eckardt, K., Schumann, G., Ihn, W. \& Tresselt, D. (1984). Microbial transformation of aklanonic acid, a potential early intermediate in the biosynthesis of anthracyclines. J Antibiot 37, 691-692.

Ward, J. M., Janssen, G. R., Kieser, T., Bibb, M. J., Buttner, M. J. \& Bibb, M. J. (1986). Construction and characterization of a series of multicopy promoter-probe plasmid vectors for Streptomyces using the aminoglycoside phosphotransferase from $\operatorname{Tn} 5$ as indicator. Mol Gen Genet 203, 468-478.

Westrich, L., Domann, S., Faust, B., Bedford, D., Hopwood, D. A. \& Bechthold, A. (1999). Cloning and characterization of a gene cluster from Streptomyces cyanogenus S136 probably involved in landomycin biosynthesis. FEMS Microbiol Lett 170, 381-387.

Ylihonko, K., Hakala, J., Niemi, J., Lundell, J. \& Mäntsälä, P. (1994). Isolation and characterization of aclacinomycin A-nonproducing Streptomyces galilaeus (ATCC 31615) mutants. Microbiology 140, 1359-1365.

Ylihonko, K., Hakala, J., Kunnari, T. \& Mäntsälä, P. (1996a). Production of hybrid anthracycline antibiotics by heterologous expression of Streptomyces nogalater nogalamycin biosynthesis genes. Microbiology 142, 1965-1972.

Ylihonko, K., Tuikkanen, J., Jussila, S., Cong, L. \& Mäntsälä, P. (1996b). A gene cluster involved in nogalamycin biosynthesis from Streptomyces nogalater: sequence analysis and complementation of early-block mutations in the anthracycline pathway. Mol Gen Genet 251, 113-120.

Ylihonko, K., Hakala, J. \& Kunnari, T. (1999). Hybrid anthracyclines from genetically engineered Streptomyces galilaeus strains. International Patent Application WO 99/58544 A1.

Yoshimoto, A., Ogasawara, T., Kitamura, I., Oki, T., Inui, T., Takeuchi, T. \& Umezawa, H. (1979). Enzymatic conversion of aclacinomycin A to Y by a specific oxidoreductase in Streptomyces. J Antibiot 32, 472-481.

Zhao, L., Ahlert, J., Xue, Y., Thorson, J. S., Sherman, D. H. \& Liu, H.-w. (1999). Engineering a methymycin/pikromycin-calicheamicin hybrid: construction of two new macrolides carrying a designed sugar moiety. J Am Chem Soc 121, 9881-9882.

Received 26 March 2002; revised 20 June 2002; accepted 9 July 2002 